\title{
Legitimación del cónyuge sobreviviente y de los herederos con ocasión de los contratos de seguros de vida grupo deudores*
}

\author{
José Fernando Ramírez Gómez**
}

\begin{abstract}
Para Citar este artículo/To cite this article
Ramirez-Gómez, José Fernando, Legitimación del cónyuge sobreviviente y de los herederos con ocasión de los contratos de seguros de vida grupo deudores, 43 RIS, 103-121 (2015). http:// dx.doi.org/10.11144/Javeriana.ris43.Icsh doi:10.11144/Javeriana.ris43.Icsh
\end{abstract}

SUMARIO

I. Introducción

II. De la legitimación

III. Los casos conocidos por la Corte Suprema de Justicia

IV. La legitimación y el contrato de seguro de vida grupo deudores

1. El contrato de seguro de vida grupo deudores

2. Los sujetos de la relación asegurativa

3. La legitimación ordinaria y extraordinaria en el seguro de vida grupo deudores

Abogado de la Universidad de Antioquia. Especialista en Derecho Procesal y Magíster en Derecho Privado de la Universidad Pontificia Bolivariana de Medellín. Catedrático de la Pontificia Universidad Javeriana. Contacto: jramirezg@sura.com.co

** Artículo de tipo reflexivo que revela un análisis crítico de la jurisprudencia de la Corte Suprema de Justicia sobre la legitimación del cónyuge sobreviviente y de los herederos con ocasión de los contratos de seguros de vida grupo deudores. 
3.1 Cuando habría legitimación ordinaria del cónyuge y los herederos

3.2 La idea de la legitimación extraordinaria de los mismos sujetos

Bibliografía

\section{RESUMEN}

A partir de la concepción procesal del presupuesto de la legitimación se aborda el estudio, teniendo como referente la casuística de la jurisprudencia, de la concreta legitimación de los herederos y del cónyuge sobreviviente con ocasión de la ocurrencia del riesgo de muerte de un específico deudor en el contrato de seguro de vida tomado por una entidad financiera con el fin de cubrir frente al señalado riesgo el saldo insoluto de las obligaciones de un grupo de personas deudoras respecto de un mismo acreedor, que lo es la entidad financiera o banco tomador.

Palabras clave: Legitimación; legitimación ordinaria; legitimación extraordinaria; cónyuge sobreviviente; heredero; riesgo de muerte; saldo insoluto del crédito; seguro de vida; grupo deudores; entidad financiera; beneficiario; asegurado; tomador; subrogación.

\section{ABSTRACT}

This article is focused on the standing and how legitimate any claim filed by heirs and the surviving spouse in the case of risk of death of an specific debtor is in the context of an insurance life policy taken by a financial entity in order to cover as to the mentioned risk the unpaid balance of obligations of a group of debtors with respect to the same creditor which is the financial entity or financial entity that has taken the insurance.

Key words: Standing, ordinary standing; extraordinary standing; surviving spouse; heir; risk of death; unpaid balance; insurance life; debtors group; financial entity; beneficiary; insured; policy subscriber; subrogation. 


\section{INTRODUCCIÓN}

Dar respuesta a la cuestión que plantea el título, es decir, averiguar por la legitimación del cónyuge supérstite y de los herederos en los casos del seguro de vida deudor (individual o colectivo), exige además de sentar unas bases teóricas concernientes al tema de la legitimación en la causa, acudir al método comparativo de los casos conocidos por la jurisprudencia, que por la variedad que presentan impide que a priori se puedan ofrecer respuestas abstractas y concluyentes.

Por lo anterior es que en este trabajo se hará un esfuerzo analítico de la jurisprudencia de la Corte Suprema de Justicia, no tanto con miras a hacer una crítica de esa práctica judicial, que al fin de cuentas es la realidad del derecho, sino con el objetivo de verificar en los distintos casos las alternativas de solución que entran en juego, y a partir de ese examen acoger o proponer fórmulas de solución justas, que en todo caso sean válidas frente a las normas del derecho positivo que inciden en el factum constatado.

Respecto de los casos evaluados (nueve últimas sentencias de la Corte Suprema de Justicia, Sala de Casación Civil), cabe hacer la siguiente anotación, necesaria para la comprensión de lo expuesto en las mismas: todas las sentencias, como bien se sabe, corresponden a la resolución de recursos extraordinarios de casación, y específicamente a cargos formulados con fundamento en la causal 1으, vía directa. Circunstancia esta que apareja, dado el carácter eminentemente dispositivo del recurso, que la cuestión fáctica haya sido extraña al conocimiento de la Corte, y que desde el punto de vista estrictamente jurídico, la Corte se haya debido mover en torno a los planteamientos del recurrente, que entonces serían los explicativos de las respuestas ofrecidas en cada uno de los casos. 
Por consiguiente, la ratio decidendi de cada sentencia habrá que considerarla en referencia al caso concreto, pero la idea está en definir si de alguno de ellos se puede colegir un stare decisis que se enarbole como precedente del cual se pueda extraer una regla general válida para los eventos futuros.

\section{DE LA LEGITIMACIÓN}

Dos son las teorías propuestas por la doctrina en relación con la legitimación: i) la sustancialista, expuesta por Chiovenda y que desde siempre ha acogido la Corte Suprema de Justicia (véanse las sentencias de 24 de julio de 1975, 6 de abril de 1976 y 28 de noviembre de 1977, entre muchas que vienen hasta ahora), según la cual la legitimación en la causa es cuestión del derecho sustancial, razón por la que se excluyó de los presupuestos procesales, constituyéndose como una cuestión de fondo, o sea de aquellas necesarias en cuanto al examen de mérito. Con ella se expresa -dice Chiovenda- "que, para que el juez estime la demanda, no basta que considere existente el derecho, sino que es necesario que considere que este corresponde precisamente a aquél que lo hace valer y contra aquél contra quien es hecho valer; o sea, considere la identidad de la persona del actor con la persona en cuyo favor está la ley (legitimación activa), y la identidad de la persona del demandado con la persona contra quien se dirige la voluntad de la ley (legitimación pasiva) ${ }^{1}$. ii) La procesal, que hace referencia no a la pretensión material que es la de la anterior propuesta sino a la "pretensión procesal", "y mira tan solo a la relación sustancial subyacente como a un punto de comparación para adecuar la subjetividad formal a la subjetividad material, a la legitimación sustancial, pudiera decirse, pero con el efecto formal de impedir la sentencia de fondo"2.

Enrico Allorio, que es uno de los más representativos expositores de esta tesis, la explica así: "La doctrina ha elaborado un concepto ya firme, técnico de la legitimación, y no puede sacrificarlo a la ambigüedad de un uso. ¿y cuál es ese concepto firme, técnico?. Él responde a una regla clara y precisa, que me será permitido recordar: la regla en virtud de la cual, nadie puede, en nombre propio accionar o ser demandado a contradecir en juicio sino por una relación de la cual se atribuya, o se le atribuya a él, la subjetividad activa o pasiva". Luego el mismo autor anota: "Cuando yo afirmo ser propietario o acreedor, y resulta luego que no lo soy, sino que lo es, en cambio, otro, no me falta la legitimación, para accionar, lo que me falta es el derecho: la propiedad o el crédito"3.

Según el mismo Allorio, y ahí estriba la diferencia con la teoría chiovendiana, condición necesaria y suficiente para que competa la legitimación, es la subjetividad, no de la relación, que es la propuesta de Chiovenda, sino de la pretensión.

1 Chiovenda, Guiseppe, Instituciones de Derecho Procesal Civil, T.I, pág. 208

2 Quintero, Beatriz, Teoría general del Proceso, ed. 3ํ, Ed. Temis, Bogotá, 2000, pág. 369

3 Allorio, Enrico, Problemas de Derecho Procesal, T. II, Ed. Europa- América, 1963, págs. 253 y 255. 
En torno a este instituto de la legitimación la doctrina distingue entre legitimación ordinaria y legitimación extraordinaria o excepcional. Por ejemplo Allorio habla de los criterios normales y excepcionales de legitimación. Al respecto dice que, "accionar o contradecir en orden a una relación de la cual no se pretenda ser, u otro no pretenda que se es, sujeto activo, ni, respectivamente, sujeto pasivo, está vedado por los criterios de la legitimación normal, pero puede ser consentido por criterios de legitimación excepcional. Estos últimos criterios presiden a institutos como la sustitución procesal y la intervención por adhesión... merced a los cuales personas que no son sujetos de la Litis...se hallan en condiciones de asumir en el proceso, la posición de partes originarias o adventicias" 4 .

Súmese a los institutos que Allorio señala, el del litisconsorcio necesario que también menciona, así como el del cuasinecesario que expresamente consagra el art. 62 del Código General del Proceso (art. 52 inc. 3 del C. de P. Civil). Esto dentro del marco del derecho procesal, pero sin olvidar el significado que para este tiene en el ámbito del estudio, como luego se verá, figuras jurídicas sustanciales como las de la subrogación legal o convencional, y la cesión de derechos, o del contrato.

Atribuirse el derecho en la demanda (pretensión) con independencia de que haya coincidencia con el titular del mismo en la relación es suficiente para que haya legitimación ordinaria, o de "criterio normal" en la terminología de Allorio. Contrariamente, si esa coincidencia no se presenta no hay legitimación normal, como cuando alguien pretende "por una relación declaradamente ajena, o por una relación que se aseguraba ser propia, pero contra persona reconocida por el actor como extraña a la relación

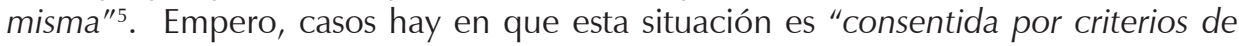
legitimación excepcional", que dan margen a la llamada "legitimación extraordinaria".

La legitimación extraordinaria debe ser "consentida" o autorizada, expresa o tácitamente por una norma legal, vale decir, un precepto que permita que alguien puede concurrir al proceso a formular una pretensión sin ser coincidentemente, ni afirmarse titular de la relación o derecho controvertido. Ejemplo característico de este tipo de legitimación es el de la llamada acción oblicua, como la que el art. 375 ord. 2 del Código General del Proceso (art. 407 núm. 2 del C. de P. Civil), otorga a los acreedores del poseedor deudor para pretender la declaración de pertenencia, a pesar de la renuencia o renuncia de este. También se proponen como casos de esta clase de legitimación la de los herederos cuando pretenden para la herencia o sucesión, o la de los cónyuges para la sociedad conyugal disuelta e ilíquida.

La distinción entre legitimación ordinaria y extraordinaria también cabe hacerla en torno a la teoría sustancialista o de Chiovenda, que es la que aplica la Corte, como ya se dijo, porque ella surge de lo legalmente establecido, pues son estas normas legales las que eventualmente permiten que una persona distinta a la titular del derecho

$4 \quad$ Allorio, Opus cit. pág. 254

$5 \quad$ Allorio, Opus cit., pág. 254 
formule la pretensión, como ocurre en los ejemplos antes señalados, conforme a las normas que consagran la respectiva autorización.

\section{LOS CASOS CONOCIDOS POR LA CORTE SUPREMA DE JUSTICIA}

En múltiples ocasiones la Corte ha tenido oportunidad de examinar el punto jurídico objeto de este estudio, seleccionándose para el mismo las sentencias emitidas el 29 de agosto de 2000, 23 de marzo de 2004, 25 de mayo de 2005, 28 de julio de 2005, 29 de septiembre de 2005, 17 de octubre de 2006, 15 de diciembre de 2008, 5 de octubre de 2009 y 16 de mayo de 2011.

\section{Sentencia de 29 de agosto de 2000}

Caso: La póliza cubría el pago del saldo de la deuda a la fecha del fallecimiento del asegurado. Sin embargo, en el seguro se instituyó como beneficiario además del banco a otra persona. Cabía esta estipulación?

Decisión: La Corte consideró que habiéndose establecido que la póliza cubría el pago del saldo de la deuda que el asegurado deudor tuviese a la fecha del fallecimiento, "no cabía estipular otros beneficiarios a título gratuito, pues nada podían reclamar para sí", porque el valor del seguro va a la par con el saldo de la deuda, de manera que nunca quedarán remanentes", y porque el valor del seguro tenía una destinación específica", como que debía ser aplicado a la deuda del asegurado fallecido"

\section{Sentencia de 23 de marzo de 2004}

Caso: Hijo del deudor asegurado suscribió el pagaré como codeudor solidario. Muerto el deudor asegurado, como la aseguradora objetó la reclamación que el banco le formuló, el deudor solidario pagó la obligación insoluta y demandó a la aseguradora alegando tener la condición de beneficiario, que el tribunal de instancia le reconoció como "subrogatario" por virtud del pago hecho.

Decisión: La Corte casó la sentencia, y por supuesto no le reconoció legitimación al demandante, porque conforme a los arts. 1579 y 1668 del C. Civil, los derechos que el acreedor inicial tenga "contra terceros derivados de las relaciones contractuales autónomas que, por serlo, no son inherentes al crédito, o que aún relacionadas con estos no suponen una garantía de pago de los mismos, a ellos no se extienden los efectos de la subrogación".

6 Corte Suprema de Justicia. Sala de Casación Civil. Expediente 6379 (MP. Jorge Santos Ballesteros; 29 de agosto de 2000) 
Ciertamente, agrega la Corte, "hay un deudor que paga y por esa razón se da la subrogación en los derechos del acreedor satisfecho, pero no alcanza la misma para que se le transmitan los derechos como beneficiario del seguro de vida deudores contra la aseguradora -tercero para el caso-, pues no solo se trata de una relación autónoma en la que se identifica plenamente los sujetos vinculados que no incluyen al actor, sino que aunque de algún modo haya estado conectada con el crédito satisfecho, no supone la presencia de la aseguradora como garante del pago de la obligación, esto es, cuanto que no se le puede calificar de tercero que se haya obligado solidaria o subsidiariamente como lo exige el artículo 1670 del C. Civil..."7.

\section{Sentencia de 25 de mayo de 2005}

Caso: La entidad financiera otorga préstamo a persona que toma seguro de vida individual y designa al banco como "primer beneficiario" y a la esposa como "beneficiario subsidiario". Muerto el asegurado la aseguradora objetó la reclamación del banco, que se limitó a requerir a la cónyuge y herederos del deudor para que cumplieran con la obligación no pagada por este, como en efecto lo hicieron para luego demandar a la aseguradora.

Decisión: La Corte admitió que los actores estaban legitimados porque siendo claro "que el riesgo que se aseguró era la pérdida de la vida del deudor", las circunstancias fácticas que halló probadas el Tribunal llevan a concluir que se presentó la subrogación que comporta la transmisión de los "derechos, acciones, privilegios, prendas e hipotecas" de un acreedor "a un tercero que paga", lo cual implica que la obligación del deudor no se extingue, sino que lo que se presenta es un simple cambio de acreedor. No es equivocado sostener con relación al seguro de vida deudores -dice la Corte"que los demandantes adquirieron la calidad de beneficiarios, a título oneroso, porque esa era precisamente la posición del Banco Cafetero en el contrato de seguros, que no es lo mismo a que fueran beneficiarios directos... ${ }^{\prime \prime}$

\section{Sentencia de 28 de julio de 2005}

Caso: Muerto el deudor asegurado la cónyuge y los herederos reclaman a la aseguradora el pago de la obligación insoluta. El Tribunal de instancia admitió la legitimación porque en su condición de cónyuge supérstite y de herederos tenían interés en la sucesión del deudor, entre otras cosas porque allí debía liquidarse la sociedad conyugal.

Decisión: En este caso la Corte luego de referirse al principio de relatividad de los contratos y argumentar que este no es absoluto porque alrededor de ellos "hay personas que ciertamente no fueron celebrantes, pero a quienes no les es indiferente

7 Corte Suprema de Justicia. Sala de Casación Civil. Expediente 14576 (MP Silvio Fernando Trejos; 23 de marzo de 2004)

8 Corte Suprema de Justicia. Sala de Casación Civil. Expediente 7198 (M.P. Jaime Alberto Arrubla Paucar; 25 de mayo de 2005) 
la suerte final del mismo", y a pesar de que el cónyuge deudor no era beneficiario del seguro, pues este era el banco, reconoce la legitimación de la viuda y de los herederos porque ellos también están "indiscutiblemente" interesados", dado que las secuelas indirectas del contrato, señaladamente el no pago del seguro, le perjudica. De la suerte de aquel contrato pende y en mucho la de la sociedad conyugal que tenía con su marido fallecido, y algo similar le acontece a los herederos ${ }^{\prime \prime}$.

\section{Sentencia de 29 de septiembre de 2005}

Caso: El banco otorgó préstamo a varias personas naturales (padres e hijos) y a una sociedad. Las personas naturales se vinculan al seguro de vida grupo deudores tomado por el banco para cubrir "suma equivalente al saldo insoluto de la obligación". Muerto el padre deudor asegurado, el banco reclamó a la aseguradora y esta objetó. Por tal circunstancia el banco ejecutó a la sociedad deudora, lo cual implica, dice la demanda de la cónyuge y los herederos, que este "ejercitó la acción de cobró y renunció al pago del siniestro", razón por la que este debe cancelarse a los demandantes por mitad, como cónyuge y herederos del deudor fallecido.

Decisión: En este caso la Corte negó la legitimación porque si el "único beneficiario" era el banco hasta concurrencia del saldo insoluto de la obligación, esto significaba que "no había defecto de beneficiarios, como tampoco remanentes, lo cual supone en los términos del artículo 1144 del Código de Comercio, una suma asegurada creciente o decreciente, en todo caso superior al saldo de la obligación"10, razón por la que la cónyuge e hijos del asegurado fallecido no pueden considerarse como "beneficiarios supletivos".

\section{Sentencia de 17 de octubre de 2006}

Caso: Como los herederos pagaron la deuda, se alegaba la ineficacia de la designación del banco como beneficiario, pues ocurrido tal hecho (pago), queda sin interés asegurable y los herederos se erigen como beneficiarios legales por la subrogación producida, conforme a los arts. 1668 y 1670 del C. Civil.

Decisión: La Corte luego de negar el argumento de la ineficacia de la cláusula que asignaba al banco la calidad de beneficiario, consideró que esta era razón suficiente para no admitir la existencia de beneficiarios supletivos conforme al art. 1142 del C. de Comercio. Así mismo, negó la pretendida subrogación legal por el pago con fundamento en el art. 1668 núm. 4 del C. Civil, pues no se cumplían los requisitos establecidos por la norma, "esto es, que quien efectué el pago sea un heredero que haya aceptado la herencia con beneficio de inventario -heredero

9 Corte Suprema de Justicia. Sala de Casación Civil. Expediente 449 (M.P. Manuel Isidro Ardila Velásquez; 28 de julio de 2005)

10 orte Suprema de Justicia. Sala de Casación Civil. Expediente 22940 (M.P. Jaime Alberto Arrubla Paucar; 29 de septiembre de 2005) 
beneficiario- y que el pago de deudas de la sucesión haya sido realizado con sus propios recursos"111.

\section{Sentencia de $\mathbf{1 5}$ de diciembre de 2008}

Caso: Muerto el asegurado y negado el pago por la aseguradora ante la reclamación del Banco acreedor y beneficiario, la cónyuge supérstite demandó a la aseguradora pretendiendo el pago para la entidad beneficiaria, pues esta objetó alegando que la póliza no aplicaba cuando se trataba de créditos a personas jurídicas y naturales, como era el caso.

Decisión: La Corte admitió la legitimación no solo de la cónyuge sobreviviente, sino extendiéndola eventualmente a "los herederos del asegurado, inclusive al socio o vocero de una sociedad, cuya vida estaba amparada, quienes en defensa de la sociedad conyugal, de la herencia o del patrimonio social, pueden exigir a la aseguradora que pague lo que debe y a quien corresponda ${ }^{12 "}$.

\section{Sentencia de 5 de octubre de $2009^{13}$}

Caso: Como la aseguradora objetó la reclamación y no pagó la obligación del deudor asegurado, ésta la canceló un tercero con dinero de la sucesión, entonces los demandantes (herederos y cónyuge), alegan su legitimación por virtud de dicho pago, en tanto se hizo con dineros de la sucesión, y además por considerarse cesionarios del beneficiario en los derechos derivados de la póliza.

Decisión: En este caso la Corte admitió la legitimación reiterando la jurisprudencia sentada en las sentencias de 28 de julio de 2005 y 17 de octubre de 2006.

\section{Sentencia de $\mathbf{1 6}$ de mayo de 2011}

Caso: El banco concedió crédito a sociedad comanditaria simple cuyo pagaré suscribió el representante legal y socio gestor, quien a su vez formuló solicitud individual de seguro de vida grupo deudores para hacer parte de la póliza tomada por el banco acreedor. Muerto el deudor asegurado no obstante la existencia de la póliza, el banco requirió a la representante de la sociedad el pago de la obligación, como en efecto lo hizo, para luego reclamarle a la aseguradora.

11 Corte Suprema de Justicia. Sala de Casación Civil. Expediente 59 (M.P. Cesar Julio Valencia; 17 de octubre de 2006)

12 Corte Suprema de Justicia. Sala de Casación Civil. Expediente 1021 (M.P. Jaime Alberto Arrubla Paucar; 15 de diciembre de 2008)

13 Corte Suprema de Justicia. Sala de Casación Civil. Expediente 03366 (M.P. Jaime Alberto Arrubla Paucar; 5 de octubre de 2009) 
Decisión: “...cuando el deudor principal -dijo la Corte- efectúa el pago del mutuo, ante la negativa de la aseguradora de cubrir el saldo..., al tenor del inciso $2^{\circ}$ del canon 1625 del Código Civil, se produce la extinción de la deuda, sin adquirir quien la satisface la calidad de "beneficiario" del aludido negocio jurídico y tampoco opera "la subrogación" porque ésta en principio favorece al tercero que cumplió aquel acto, según el precepto 1666 ibídem, y no al obligado"14.

\section{LA LEGITIMACIÓN Y EL CONTRATO DE SEGURO DE VIDA GRUPO DEUDORES}

\section{El contrato de seguro de vida grupo deudores}

Antes de abordar en concreto el estudio de la legitimación con apoyo en la teoría procesal inicialmente propuesta, y los elementos fácticos y de doctrina que ofrece la jurisprudencia de la Corte Suprema de Justicia, necesario resulta tener claridad acerca de la concepción legal del seguro de vida objeto del examen.

Mediante este seguro se ampara el riesgo de muerte o de incapacidad de los deudores de las entidades financieras con fundamento en lo dispuesto en el art. 1137 del Código de Comercio, en tanto reconoce la existencia de "interés asegurable" en el caso de que la muerte o la incapacidad de una persona "pueda aparejarle un perjuicio económico" a otra (núm. 3), que en el evento de los deudores de los bancos estaría concretado al no pago de la obligación a cargo del deudor asegurado. Argumento este que viene a consolidarse con el art. 1144 ibídem, cuando estatuye que en los seguros sobre la vida del deudor, el acreedor solo recibirá una parte del seguro igual al monto no pagado de la deuda, que es la misma exigencia que plasman el Estatuto Orgánico del Sistema Financiero y las diversas Circulares y Resoluciones que la Superintendencia Financiera ha expedido regulando este tipo de aseguramiento.

Es un seguro de vida y no un seguro de crédito, mediante el cual se cubre contra el riesgo de la muerte o de la incapacidad total y permanente, el saldo insoluto del crédito de un grupo de personas deudoras de un mismo acreedor. Bajo esta modalidad de seguro de vida- explica la doctrina- "el tomador es la respectiva entidad financiera y como es un seguro de carácter colectivo, en frente de carteras hipotecarias, el grupo asegurado lo constituyen los deudores hipotecarios con créditos vigentes, entendiéndose como tales las personas naturales, los socios de las sociedades de responsabilidad limitada, en comandita, de hecho y, en general, quien tenga ese carácter de deudor o sea responsable del pago de un crédito hipotecario en favor de la entidad financiera, incluyendo aquellas hipótesis en que la operación del crédito se radica en cabeza de dos o más personas (caso en el cual el seguro puede contratarse para todas en forma proporcional a su participación en los ingresos demostrados, o para todos en el 100\%

14 Corte Suprema de Justicia. Sala de Casación Civil. Expediente 9221 (M.P. Ruth Marina Díaz 16 de mayo de 2011) 
de la obligación, siempre y cuando todas tengan interés asegurable real -art. 1045 del C. de Co.), evento en el cual quedarán amparados por la misma aseguradora (sic) y con idénticos amparos del asegurado principal"15.

No siendo un seguro de crédito porque el riesgo amparado no es el incumplimiento de la obligación, ni mucho menos la insolvencia del deudor, irrelevante resulta para la configuración del siniestro si el deudor está o estaba en condiciones económicas de pagar la obligación. Por consiguiente los únicos detonantes para la afectación de la póliza son la muerte o la incapacidad total y permanente, que sin otra consideración determinan la obligación de la aseguradora de cancelar el valor asegurado, que no es otro que el saldo insoluto del crédito, y el derecho correlativo de la entidad financiera de formular reclamación pretendiendo el pago de dicha obligación.

\section{LOS SUJETOS DE LA RELACIÓN ASEGURATIVA}

Además de la naturaleza jurídica del contrato objeto de examen, otro elemento que lógicamente contribuye a la respuesta de la cuestión planteada, esto es, la de la legitimación, es el de los sujetos de la relación sustancial que se establece con ocasión de la celebración del contrato de seguro colectivo de vida deudores.

Como es claro, porque así lo consagra el art. 1037 del Código de Comercio, las partes del contrato de seguro son el asegurador, o sea la persona jurídica que asume los riesgos, y el tomador, o sea la persona que, obrando por cuenta propia o ajena, traslada los riesgos.

El tomador cuando actúa por cuenta propia amparando su propio interés, adquiere la calidad de asegurado, e inclusive la de beneficiario cuando acaecido el siniestro sea él quien tenga derecho a recibir la correspondiente indemnización. De manera que tomador, asegurado y beneficiario pueden ser una misma persona, pero nada obsta para que sean distintas, como ocurre en los seguros individuales sobre la vida de un tercero, donde este, previo su consentimiento, es el asegurado y otros los beneficiarios (art. 1137 núm. 3 del Código de Comercio).

En los seguros de personas, entonces, el asegurado es la persona cuya vida o integridad corporal se ampara con el contrato, y el beneficiario quien tiene derecho a la prestación asegurada, que bien puede ser el tomador, o el mismo asegurado, o la persona que la póliza o la ley señale como beneficiario (art. 1142 ibídem).

Tratándose del seguro de vida grupo deudores (seguro colectivo), el tomador es el banco o la entidad financiera que otorga el crédito a una persona natural que en su condición de deudor se adscribe o vincula a la póliza que cubre los riegos de muerte o

15 Narváez Bonnet Jorge Eduardo. Legitimación de la viuda y de los herederos, bajo el seguro de vida grupo deudores, Revista Ibero - Latinoamericana de Seguros, pág. 80. 
incapacidad total y permanente, siendo el valor del interés asegurado el saldo insoluto de la obligación al momento de ocurrir el siniestro (arts. 1137 núm. 3, 1138 y 1144 del Código de Comercio).

La Superintendencia Bancaria en Resolución 2735 de 1990, art. 6º, no vigente por anulación del Consejo de Estado, pero importante como dato histórico, al regular la póliza de deudores objeto de estudio en cuanto a las personas intervinientes, decía en el numeral 1 que, "El tomador del seguro de vida grupo en las pólizas de deudores será únicamente el acreedor", que es la entidad financiera, y que, "2. El beneficiario en estos seguros será, a título oneroso, el tomador en concurrencia del saldo insoluto de la deuda".

Respecto de los beneficiarios, de acuerdo con lo dispuesto por los arts. 1141 y 1142 del Código de Comercio, es dable identificar los beneficiarios a título gratuito u oneroso, los convencionales nominados en la póliza y los supletivos o legales, o sea aquellos a quienes le ley misma les asigna tal condición por ausencia de designación contractual, o porque la designación hecha en la póliza sea ineficaz o quede sin efecto por cualquier causa, caso en el cual el vacío lo suple directamente la ley asignándole la calidad de beneficiarios al cónyuge del asegurado, en la mitad del seguro, y a los herederos de éste en la otra mitad.

La distinción entre beneficiario a título gratuito y a título oneroso, pasa porque la designación del tomador tenga como causa la "mera liberalidad", pues si este no es el móvil entonces se entenderá a título oneroso. Pero si en la póliza nada se estipula, "se presumirá que el beneficiario ha sido designado a título gratuito", declara la parte final del art. 1141. Desde luego que en los seguros de vida grupo deudores, la entidad crediticia es beneficiaria a título oneroso, como repetidamente lo ha dicho la jurisprudencia y la doctrina de la Superintendencia, empezando por la Resolución a que ahora se hacía referencia.

\section{LA LEGITIMACIÓN ORDINARIA Y EXTRAORDINARIA EN EL SEGURO DE VIDA GRUPO DEUDORES}

\subsection{Cuando habría legitimación ordinaria del cónyuge y los herederos}

Antes se explicó que en materia de legitimación en causa la doctrina daba cuenta de dos teorías, la sustancialista de Chiovenda, acogida por la Sala de Casación Civil de la Corte Suprema de Justicia en múltiples sentencias, siendo una de las primeras la proferida el 6 de abril de 1976, donde sostuvo que, "Según concepto de Chiovenda, acogido por la Corte, la legitimatio ad causam consiste en la identidad de la persona del actor con la persona a la cual la ley concede la acción (legitimación activa) y la identidad de la persona del demandado con la persona contra la cual es concedida la acción (legitimación pasiva)...". " Para que esa pretensión -agrega seguidamente la Corte- sea acogida en la sentencia es menester, entre otros requisitos, que se 


\section{haga valer por la persona en cuyo favor establece la ley sustancial el derecho que se reclama en la demanda, y frente a la persona respecto de la cual ese derecho puede ser reclamado" (negrilla fuera de texto).}

La otra teoría a la cual se hizo referencia es la postura formal o procesal pregonada por varios reconocidos doctrinantes, como Carnellutti, Redenti, Allorio y Devis Echandía, entre los nacionales, quienes reducen la legitimación en la causa a la afirmación formal o procesal de ser el titular del derecho objeto de la pretensión, u obligado desde el punto de vista pasivo. Luego, como lo anota Allorio en aparte ya invocado, "Cuando yo afirmo ser propietario o acreedor, y resulta luego que no lo soy, sino que lo es, en cambio, otro, no me falta la legitimación, para accionar, lo que me falta es el derecho: la propiedad o el crédito". Basta entonces autoafirmarse procesalmente como titular de la relación sustancial o atribuirle esa subjetividad al demandado para que se dé por descontada la legitimación por activa y pasiva, con independencia de que probatoriamente tenga asidero la coincidencia, puesto que esa es ya una "cuestión de mérito" que tiene que ver con el resultado favorable de la pretensión, que es el examen de segunda fase que sigue a la verificación de los presupuestos materiales para la sentencia de mérito, como lo es la legitimación en causa, tanto por activa como por pasiva. Distinto a lo considerado por la teoría sustancialista que al identificar actor con titular del derecho y demandado con obligado, estima la cuestión como de fondo, dado su ligamen con el derecho sustancial, y por ende propugna por una sentencia de mérito desfavorable para cuando no se da la legitimación.

Empero, a pesar de las diferencias existentes entre ambas teorías (por la forma de verificar la legitimación, por su naturaleza y por el resultado), lo cierto es que en ambas habría lugar a distinguir entre legitimación ordinaria o normal y legitimación extraordinaria o excepcional, y a dejar por sentado que en cualquiera de ellas la institución tiene un vínculo estricto con la ley, bien la general y abstracta, o la particular y concreta del contrato o de la situación jurídica respectiva, pues de ella es de donde se infiere la legitimación, ya como identidad coincidente, ora como mera afirmación formal de ostentar la condición necesaria que la ley o el contrato establece. Sin embargo, cabe reiterarlo para claridad de lo que luego se concluya, que la legitimación extraordinaria o excepcional solo puede surgir de una norma legal propiamente dicha, excluyéndose por consiguiente la norma contractual. Los supuestos de legitimación extraordinaria son muy variados y diversos entre sí, -dice la doctrina- "con el único común denominador de la falta de coincidencia de titularidades y de su autorización legal especial; siempre que alguien, porque una norma así lo estatuya expresa o tácitamente pueda presentarse al proceso como titular de la relación procesal sin afirmarse al mismo tiempo titular del derecho a debatirse, se dará una hipótesis de legitimación extraordinaria o anormal: legitimación por categorías, litisconsorcio necesario, intervención en proceso de los patrimonios autónomos, la así denominada pretensión oblicua, legitimación concedida al dueño del bien para debatir asuntos que conciernen, por ejemplo, a un contrato de arrendamiento, etc ${ }^{\prime \prime}{ }^{16}$

16 Quintero, Beatríz, Opus Cit., pág. 378 
Desde luego que la consagración legal expresa o tácita solo se demanda de la legitimación extraordinaria, porque la ordinaria o normal fácilmente se deduce de las relaciones jurídicas que los sujetos establecen, por ejemplo los contratos, donde naturalmente los legitimados para debatir acerca de los derechos y obligaciones que de ellos dimanan son las partes contractuales. Con todo, llenos están los códigos sustantivos de normas que legitiman ordinariamente, por ejemplo los arts. 946, 950, 951, 952, 974, 1321, 1546, 2341 del Código Civil, entre muchas más de este y otros estatutos.

Ahora bien, de acuerdo con el análisis precedente aflora una primera conclusión: en el caso del seguro de vida grupo deudores la legitimación ordinaria o normal, y primaria, está en cabeza de la entidad financiera que ostenta la condición de beneficiaria contractual a título oneroso, puesto que ella es la que tiene derecho a reclamar del asegurador el pago de la prestación, es decir, el saldo insoluto de la obligación del asegurado fallecido o incapacitado total y permanentemente.

Por cuanto en el tipo de contrato que es objeto de examen el valor del interés asegurable está limitado por el saldo de la obligación al fallecimiento del deudor, prima facie debe descartarse la posibilidad de que otras personas, como el cónyuge sobreviviente o los herederos, concurran como beneficiarios a algún título y con derecho a reclamar parte de la prestación, porque como bien lo explicó la Corte en las sentencias de 29 de agosto de 2000 y 29 de septiembre de 2005, como el valor del seguro va a la par con el saldo de la deuda del asegurado, no hay lugar a que queden "remanentes", y por ende excluida queda la opción de la aparición de otros beneficiarios legitimados ordinariamente para pretender el pago de la prestación. Claro está que tratándose de un seguro de vida individual del deudor, otra es la solución conforme lo define el art. 1144 del Código de Comercio, porque en ese caso no opera el límite del "monto no pagado de la deuda", que es apenas el derecho del acreedor, puesto que el resto, saldo o remanente, debe ser "entregado a los demás beneficiarios", quienes están legitimados ordinariamente para pretender el pago.

Lo expuesto también permite concluir que para estar legitimado ordinariamente se debe ser beneficiario a cualquier título, esto es, porque contractualmente así se estipuló, como normalmente ocurre con el banco, o porque la ley entra a suplir las deficiencias contractuales, dando cabida a los llamados "beneficiarios supletivos", que conforme al art. 1142 del Código de Comercio nacen porque i) el contrato no designa beneficiario, o ii) la designación contractual es ineficaz o queda sin efecto por cualquier causa. Eventos en los cuales entran a tener la calidad de beneficiarios el cónyuge del asegurado y los herederos, por mitades del seguro.

Esa calidad de beneficiario es la que también adquieren el cónyuge y/o los herederos cuando muerto el asegurado proceden a pagarle al Banco el saldo insoluto de la obligación del causante deudor, ante la objeción o negativa del asegurador a cumplir con la prestación que del contrato de seguro emerge. Esto por virtud de la subrogación convencional que reglamentan los arts. 1666, 1667, 1669 y 1670 del Código Civil, porque la recepción del pago por parte del Banco implica la subrogación voluntaria de 
todos los derechos y acciones que él tenía frente al deudor de la obligación aseguraticia, lo que en palabras del art. 1670 significa que el tercero que paga, llámese cónyuge y/o herederos, u otro cualquier sujeto, se torna en "nuevo acreedor" (beneficiario por subrogación), y por lo tanto titular de "todos los derechos, acciones y privilegios, prendas o hipotecas del antiguo (acreedor) contra el deudor principal (asegurador en el caso) como contra cualesquiera terceros, obligados solidaria y subsidiariamente a la deuda".

Para que esta subrogación personal ocurra, en tanto se muta la persona del acreedor original por la persona del nuevo acreedor es necesario que exista una convención entre el acreedor y el tercero que paga, que la subrogación se haga en la carta de pago de manera expresa y que se le notifique al deudor. Por consiguiente son indispensables los consentimientos del acreedor y de quien paga, siendo ante todo fundamental el del primero que es el que subroga, como titular que es de los derechos trasmitidos.

Se discrepa así del razonamiento expuesto por la Corte en la sentencia de 23 de marzo de 2004, donde a pesar de admitir que el factum conocido daba lugar a la "subrogación en los derechos del acreedor satisfecho", restringió su alcance en cuanto a los derechos que como "beneficiario del seguro de vida deudores contra la aseguradora" tenía el antiguo acreedor (banco), bajo el argumento, incorrecto, que el contrato de seguro era "una relación autónoma en la que se identifica plenamente los sujetos vinculados que no incluyen al actor...", es decir, al tercero que paga.

Este argumento, el de la autonomía entre la relación del crédito pagado y la relación sustancial del contrato de seguro, para hacer ver que el tercero pagador no es sujeto de esta última, carece de la mínima sindéresis lógica porque es que la obligación que el tercero procede a extinguir no es otra que la generada por el contrato de seguro al ocurrir la condición del siniestro, pero íntimamente ligada a la obligación debida por el asegurado en cuanto es ella la amparada. De manera que no se trata de pagar cualquier obligación, medio "conectada" con el contrato de seguro, como parece decirlo la sentencia de la Corte, sino la obligación misma que tiene como fuente dicho contrato, contando con la aquiescencia del acreedor de ella, que es nadie menos que el tomador y beneficiario en el contrato de seguro.

Contrariamente a lo explicado por la Corte, es necesario que el tercero que pague no esté vinculado con la obligación para que pueda hablarse de subrogación convencional, pues si existe ese vínculo lo que se presenta es la subrogación legal si la situación se enmarca en alguna de las hipótesis que consagra el art. 1668, o no hay subrogación, como bien ocurre cuando paga el codeudor solidario porque en ese caso extingue su obligación propia, y ya entonces no hay nada que subrogar frente a la aseguradora, como lo consideró la Corte en la sentencia de 16 de mayo de 2011.

Hecho ese pago en la forma como lo exige el art. 1669, se dan los efectos previstos por el art. 1670, que es el que permite sostener que el "acreedor nuevo" por virtud de la subrogación adquiere la condición de beneficiario (derivado) que antes tenía el beneficiario contractual, es decir, el antiguo acreedor, quedando así con una 
legitimación ordinaria para pretender de la aseguradora el pago de la obligación que ella no honró.

Vale la pena tener en cuenta que en contraposición con la sentencia de 23 de marzo de 2004, la Corte en la sentencia de 25 de mayo de 2005 hizo un razonamiento acorde con lo que en este trabajo se comenta, admitiendo el fenómeno de la subrogación convencional con ocasión del pago hecho por la cónyuge o los herederos con las condiciones legalmente establecidas, caso en el cual, dice la Corte, estos adquieren "la calidad de beneficiarios, a título oneroso, porque esa era precisamente la posición del Banco ...".

De otro lado, igualmente puede darse el caso de la subrogación legal que consagra el art. 1668 núm. 4 del Código Civil, con ocasión del pago hecho por el heredero beneficiario, o sea aquél que ha aceptado la herencia con beneficio de inventario, que entre otras cosas es una presunción legal (arts. 1304 del Código Civil y 488 núm. 4 del Código General del Proceso). Esta subrogación operaría en el caso de que el heredero beneficiario pague más de lo que le corresponde de acuerdo con su cuota hereditaria, pues si el pago es por suma equivalente al monto de esa cuota, o menos, no hay lugar a la subrogación porque está pagando lo que debe, por cuanto ese es el efecto del beneficio de inventario. En cambio, sí con dinero propio pagase la obligación insoluta del deudor asegurado por encima del valor de su cuota, operaría la subrogación legal que la norma establece, quedando legitimado para pretender de la aseguradora el pago con el límite de la afección patrimonial propia, obviamente en su condición de beneficiario por virtud de la subrogación legal que ha quedado descrita.

\subsection{La idea de la legitimación extraordinaria de los mismos sujetos}

Antes que una afirmación lo que en este acápite cabe formular es un interrogante: ¿Estarán el cónyuge y/o los herederos del asegurado legitimados extraordinariamente para pretender de la aseguradora el pago de la respectiva prestación con ocasión del contrato de seguro de vida grupo deudores?.

Anteriormente se explicó, invocando las doctrinas nacional y externa, que la legitimación extraordinaria, excepcional o anormal, según las distintas denominaciones a las que se acude, se presenta cuando una persona que no es sujeto de la litis puede asumir en el proceso la posición de parte formulando la respectiva pretensión procesal. Igualmente se advirtió que para que tal situación se dé, se precisa rigurosamente de una norma legal que expresa o tácitamente consienta o autorice tal conducta, vale decir, se repite, un precepto legal "que permita que alguien puede concurrir al proceso a formular una pretensión sin ser coincidentemente, ni afirmarse titular de la relación o derecho controvertido".

Tratándose del cónyuge y herederos del asegurado cabría averiguar si estos, con independencia de los casos de subrogación analizados, podrían pretender de la asegu- 
radora el pago de la respectiva prestación cuando el banco por cualquier circunstancia no ejerce directamente la acción formulando dicha pretensión.

Ocurre en la práctica que en algunas ocasiones el banco acreedor no demanda a la aseguradora después de que esta ha objetado la reclamación, porque considera seria y fundada la objeción, o porque cuenta con otras garantías que hace valer, incluida la persecución del pago por otros codeudores, o por simple negligencia, o por solidaridad con la aseguradora cuando ambas entidades pertenecen a un mismo grupo económico.

Todas estas variables avivan la pregunta formulada: ¿Podrá el cónyuge y/o los herederos demandar a la aseguradora pretendiendo el pago de la obligación debida por el asegurado para el banco acreedor?.

El planteamiento pone de presente un eventual caso de legitimación extraordinaria, a modo de acción oblicua que necesariamente exigiría, como ha quedado explicado, la existencia de un precepto legal que expresa o tácitamente autorizara la legitimación excepcional o extraordinaria. Precepto que no existe en la legislación colombiana, porque ni siquiera hay una norma de carácter general que autorice a los acreedores a instaurar contra terceros las acciones que tendría el deudor, mucho menos la hay para los herederos o el cónyuge sobreviviente que cobije casos como el descrito. Es que este tipo de acción oblicua o indirecta, como ejemplo reconocido de legitimación extraordinaria, solo cabe en los casos específicos que la ley consagra, valiendo como ejemplos los señalados por los arts. 1295, 1451, 2022, 2023 y 2513, adicionado por el art. 2 o de la ley 791 de 2002, del Código Civil, en todos los cuales los acreedores del deudor pretenden, reclaman o hacen valer los derechos que este renuncia con el fin de salvaguardar sus créditos.

El tratadista Guillermo Ospina Fernández ratifica lo expuesto al explicar que al contrario del Código Civil Francés, donde existe el artículo 1166, consagratorio de una acción oblicua de carácter general17, en el Código de Colombia el señor Bello "optó por la institución romana de la subrogación de los acreedores en los bienes, derechos y acciones del deudor, como una medida de orden procesal más que sustancial, encaminada a asegurar la custodia y administración del patrimonio del deudor hasta que los activos del patrimonio aprehendidos en un proceso de ejecución sean adjudicados al rematante, acreedor o tercero, momento en el cual este, como es obvio, entra ya a administrarlos como propios, y no en nombre del deudor. Esta es la razón por la cual no se trajo al Código mencionado el art. 1166 de su modelo francés que consagró la acción oblicua, versión deformada del sistema romano"18.

17 Art. 1166. "Todos los acreedores pueden ejercitar todos los derechos y acciones del deudor, a excepción de aquellos que estén vinculados exclusivamente a su persona"

18 Ospina Fernández Guillermo, Régimen General de las Obligaciones, ed. 3ํㅡ, Ed. Temis, Bogotá, 1980, págs. 211 y 212 
Descartada queda así una legitimación extraordinaria que les permitiera al cónyuge y herederos del asegurado fallecido, pretender de la aseguradora, no en nombre propio, sino en vez del banco y para él, el pago de la obligación insoluta del asegurado.

La Corte en dos sentencias, de 28 de julio de 2005 y de 15 de diciembre de 2008, admitió la legitimación por la que se averigua, sin calificarla de extraordinaria, prevalida del "interés" "indiscutible" que la viuda y los herederos tienen en la liquidación de la sociedad conyugal y en la herencia, "dado que las secuelas indirectas del contrato, señaladamente el no pago del seguro, le perjudica". Toda la argumentación orientada por la idea de que el principio de la relatividad de los contratos no es absoluto, pues al lado de ellos hay terceros, como lo serían el cónyuge y los herederos del deudor fallecido, que reciben efectos de los mismos.

Nadie podría poner en duda que el no pago de la obligación asegurada afectaría desde un punto de vista eminentemente práctico (utilidad en palabras de Rocco), los intereses de la viuda y de los herederos en las liquidaciones de la sociedad conyugal y de la herencia, pues ese sería un pasivo que gravaría esos patrimonios autónomos. Sin embargo, de este aserto no se puede colegir lo que en ambas sentencias la Corte concluyó, no solo porque al tratarse de legitimaciones extraordinarias se precisaría de la norma que autorizara la legitimación, la cual no existe, como ya se explicó, sino porque esa condición apenas les permitiría intervenir como coadyuvantes (terceros) en el proceso que el mismo banco adelantara contra la aseguradora (art. 71 del Código General del Proceso y art. 52 del Código de Procedimiento Civil). De suerte que no se ve con que lógica jurídica se pudiera justificar el paso de la débil intervención adhesiva a la de parte, así sea de manera indirecta, que es la característica de la acción oblicua, si es que se quiere hablar de ella en los casos examinados por la Corte, que desde la mera perspectiva del recurso de casación también muestran graves falencias, como han tenido oportunidad de explicarlas algunos comentaristas de la jurisprudencia ${ }^{19}$.

En todo caso, para lo que es objeto de este estudio, lo claro es que en esos dos eventos la legitimación que la Corte afirmó no aparece por ningún lado, salvo que se diga que el derecho viviente es ese el de los casos resueltos con independencia de la solvencia teórica de la decisión, que es la que aquí se ha tratado de poner en duda, dejando de lado los argumentos de equidad que otros aducen para justificar las decisiones, o las voces que ven en las circunstancias fácticas que rodean los casos conductas de responsabilidad extracontractual o de abuso del derecho que orientarían el camino a seguir por los interesados, pero que es arista de la problemática que supera los fines del presente trabajo, porque en esos casos, la calidad de cónyuge sobreviviente o de heredero pasa a un segundo plano para los efectos configurativos de la legitimación, pues el elemento determinante de la misma lo viene a constituir la condición de perjudicado por la conducta supuestamente abusiva o culposa que se imputa a la aseguradora que sin fundamento objeta la reclamación, o al banco que

19 Ordoñez Ordoñez Andrés, Revista Ibero- Latinoamericana de Seguros, No. 23, págs. 269 a 284 . 
sin motivo justo se abstiene de demandar el cumplimiento de la prestación asegurada. Pero, sea lo que fuere, lo cierto es que en los sendos casos que la Corte resolvió ese no fue el debate, y de ahí la objeción que desde el ángulo de la pura casación algunos hacen a las referidas sentencias.

\section{BIBLIOGRAFIA}

\section{Libros}

Allorio, Enrico, Problemas de Derecho Procesal, T. II, Ed. Europa- América, 1963, págs. 253 y 255.

Chiovenda, Guiseppe, Instituciones de Derecho Procesal Civil, T.I, pág. 208

Narváez Bonnet Jorge Eduardo. Legitimación de la viuda y de los herederos, bajo el seguro de vida grupo deudores, Revista Ibero - Latinoamericana de Seguros, pág. 80.

Ordoñez Ordoñez Andrés, Revista Ibero- Latinoamericana de Seguros, No. 23, págs. 269 a 284.

Ospina Fernández Guillermo, Régimen General de las Obligaciones, ed. 3oㅡ, Ed. Temis, Bogotá, 1980, págs. 211 y 212

Quintero, Beatriz, Teoría general del Proceso, ed. 3ō, Ed. Temis, Bogotá, 2000, pág. 369

\section{Jurisprudencia (Colombia)}

Corte Suprema de Justicia. Sala de Casación Civil. Expediente 6379 (M.P. Jorge Santos Ballesteros; 29 de agosto de 2000)

Corte Suprema de Justicia. Sala de Casación Civil. Expediente 14576 (M.P. Silvio Fernando Trejos; 23 de marzo de 2004)

Corte Suprema de Justicia. Sala de Casación Civil.

Expediente 7198 (M.P. Jaime Alberto Arrubla Paucar; 25 de mayo de 2005)

Corte Suprema de Justicia. Sala de Casación Civil. Expediente 449 (M.P. Manuel Isidro Ardila Velásquez; 28 de julio de 2005)

Corte Suprema de Justicia. Sala de Casación Civil. Expediente 22940 (M.P. Jaime Alberto Arrubla Paucar; 29 de septiembre de 2005)

Corte Suprema de Justicia. Sala de Casación Civil. Expediente 59 (M.P. Cesar Julio Valencia; 17 de octubre de 2006)

Corte Suprema de Justicia. Sala de Casación Civil. Expediente 1021 (M.P. Jaime Alberto Arrubla Paucar; 15 de diciembre de 2008)

Corte Suprema de Justicia. Sala de Casación Civil. Expediente 03366 (M.P. Jaime Alberto Arrubla Paucar; 5 de octubre de 2009)

Corte Suprema de Justicia. Sala de Casación Civil. Expediente 9221 (M.P. Ruth Marina Díaz 16 de mayo de 2011) 
